\title{
Combined value of exhaled nitric oxide and blood eosinophils in chronic airway disease: the Copenhagen General Population Study
}

\author{
Yunus Çolak ${ }^{1,2,3}$, Shoaib Afzal ${ }^{1,2,3}$, Børge G. Nordestgaard ${ }^{1,2,3,4}$, \\ Jacob L. Marott ${ }^{2,3}$ and Peter Lange $2,3,4,5,6$ \\ Affiliations: ${ }^{1}$ Dept of Clinical Biochemistry, Herlev and Gentofte Hospital, Copenhagen University Hospital, \\ Herlev, Denmark. ${ }^{2}$ The Copenhagen General Population Study, Herlev and Gentofte Hospital, Copenhagen \\ University Hospital, Herlev, Denmark. ${ }^{3}$ The Copenhagen City Heart Study, Frederiksberg Hospital, \\ Copenhagen University Hospital, Copenhagen, Denmark. ${ }^{4}$ Faculty of Health and Medical Sciences, University \\ of Copenhagen, Copenhagen, Denmark. ${ }^{5}$ Dept of Public Health, Section of Social Medicine, University of \\ Copenhagen, Copenhagen, Denmark. ${ }^{6}$ Dept of Internal Medicine, Section of Respiratory Medicine, Herlev and \\ Gentofte Hospital, Copenhagen University Hospital, Herlev, Denmark.
}

Correspondence: Peter Lange, Dept of Public Health, Section of Social Medicine, University of Copenhagen, Øster Farimagsgade 5, Postal Box 2099, DK-1015 Copenhagen K, Denmark. E-mail: Peter.Langedsund.ku.dk

@ERSpublications

Combination of exhaled nitric oxide and blood eosinophils may have an additive value in chronic airway disease http://ow.ly/jUmj30kod8B

Cite this article as: Çolak Y, Afzal S, Nordestgaard BG, et al. Combined value of exhaled nitric oxide and blood eosinophils in chronic airway disease: the Copenhagen General Population Study. Eur Respir J 2018; 52: 1800616 [https://doi.org/10.1183/13993003.00616-2018].

ABSTRACT We investigated whether the combination of increased exhaled nitric oxide fraction (FeNO) level and blood eosinophil count had an additive value in chronic airway disease in the general population.

We included 4677 individuals aged 20-100 years from the Copenhagen General Population Study. Based on pre- and post-bronchodilator spirometry, self-reported asthma and smoking history, participants were subdivided into healthy never-smokers $(n=1649)$, healthy ever-smokers $(n=1581)$, asthma $(n=449)$, chronic obstructive pulmonary disease (COPD) $(n=404)$, asthma-COPD overlap (ACO) $(n=138)$ and nonspecific airflow limitation $(\mathrm{n}=456)$.

Compared to individuals with $\mathrm{FeNO}<25 \mathrm{ppb}$ and blood eosinophils $<0.3 \times 10^{9} \mathrm{cells} \cdot \mathrm{L}^{-1}$, age- and sexadjusted odds ratios $(95 \% \mathrm{CI})$ for wheezing were 1.54 (1.29-1.84) for individuals with $\mathrm{FeNO} \geqslant 25 \mathrm{ppb}$ or blood eosinophils $\geqslant 0.3 \times 10^{9}$ cells $\cdot \mathrm{L}^{-1}$ and 2.14 (1.47-3.10) for individuals with $\mathrm{FeNO} \geqslant 25 \mathrm{ppb}$ and blood eosinophils $\geqslant 0.3 \times 10^{9}$ cells $\cdot \mathrm{L}^{-1}$. Corresponding odds ratios were $1.13(0.91-1.41)$ and $1.83(1.20-2.79)$ for sputum production, $1.54(1.22-1.94)$ and $3.26(2.16-4.94)$ for asthma, $1.03(0.80-1.32)$ and $0.67(0.36-$ 1.27) for COPD and $1.32(0.88-1.96)$ and 2.14 (1.05-4.36) for ACO. Among individuals reporting respiratory symptoms, predicting the type of chronic airway disease did not differ between the two biomarkers and did not improve by combining them.

Combination of FeNO and blood eosinophils may have an additive value in characterising chronic airway disease in the general population but still needs to be investigated further with regard to clinical application. 


\section{Introduction}

Eosinophilic airway inflammation is increasingly recognised as an important feature of patients that are highly responsive to treatment with corticosteroids $[1,2]$. Both fraction of exhaled nitric oxide (FeNO) level and blood eosinophil count have been suggested as biomarkers to determine and quantify the degree of eosinophilic airway inflammation [3]. Although FeNO and blood eosinophils may be a measure of the same inflammatory component, the two biomarkers seem to be regulated by different inflammatory pathways, which is supported by the weak correlation between them and by the results from large clinical trials of treatments targeting type 2 T-helper cell cytokine-driven inflammation [4-9]. Therefore, it has been suggested that they be used as complementary biomarkers of a clinically important pattern of inflammation $[5,10,11]$. However, studies on the clinical importance of combining these two biomarkers are still limited.

In the present study, we investigated whether the combination of increased FeNO level and blood eosinophil count had an additive value in chronic airway disease in the general population.

\section{Methods}

Study design and participants

We included 5578 individuals aged 20-100 years from the second examination of the Copenhagen General Population Study (CGPS), a population-based prospective cohort study initiated in April 2014 with ongoing enrolment. In the second examination, individuals are invited from the same areas as the first examination (2003-2014), meaning that some are newly invited and some were examined in the first examination $[12,13]$. Individuals living in the Capital Region of Denmark were randomly selected from the National Danish Civil Registration System to reflect the adult Danish population by using the unique identification number provided to everyone at birth or immigration. Among individuals aged 20-39 years, $\sim 25 \%$ of those eligible were randomly selected and invited, whereas all eligible individuals aged $\geqslant 40$ years were randomly selected and invited. All participants completed a comprehensive questionnaire, underwent a physical examination and provided blood for biochemical analyses. Questionnaires were reviewed in detail at the day of attendance by a healthcare professional together with the participant. The study was approved by Herlev and Gentofte Hospital (Herlev, Denmark) and a Danish ethical committee, and was conducted according to the Declaration of Helsinki. All participants provided written informed consent.

\section{Exhaled nitric oxide and blood eosinophils}

FeNO levels in the expiratory volume were obtained using an online measurement technique with the portable hand-held device NIOX VERO (Aerocrine, Solna, Sweden), in accordance with the recommendations from the European Respiratory Society (ERS) and American Thoracic Society (ATS) $[12,14]$. The apparatus has a lowest detection limit of $5 \mathrm{ppb}$ and a measurement range of 5-300 ppb. Measurements were performed with individuals in a sitting position without the use of a nose-clip, as this may lead to accumulation of nitric oxide in the nasal region and promote leakage via the posterior nasopharynx [14]. During the inspiration phase, individuals were required to inhale to their total lung capacity through the mouthpiece, which possesses a protective filter, in order to avoid environmental containment. During the exhalation phase, individuals were guided via an animated interface on the apparatus to maintain a correct constant expiratory flow rate. The apparatus did not analyse the expiratory volume for a FeNO level if individuals failed to sustain a correct constant expiratory flow rate and automatically required the measurement to be repeated. Since spirometry and reversibility testing may affect FeNO levels in the airways [14], measurement of FeNO was always performed before spirometry and reversibility testing. Healthcare professionals were trained on proper use of standard operating procedures in the measurement of $\mathrm{FeNO}$ and certified on three occasions by more experienced healthcare professionals. Maintenance of the apparatus was undertaken regularly, as recommended by the manufacturer. A FeNO level $<25 \mathrm{ppb}$ was considered as normal and $\geqslant 25 \mathrm{ppb}$ as increased, in accordance with the recommendations from the ATS [15].

White blood cell counts were measured on fresh samples using the ADVIA 120 Hematology System (Siemens Healthcare, Munich, Germany). Analyses were subjected to daily precision testing using internal quality control material and monthly accuracy testing using an external control quality programme [12]. Blood eosinophil counts were reported in $\times 10^{9}$ cells $\cdot \mathrm{L}^{-1}$ together with other leukocyte subpopulations, and percentage of total white blood cell count was calculated. A blood eosinophil count $<0.3 \times 10^{9}$ cells. $\mathrm{L}^{-1}$ was considered normal and $\geqslant 0.3 \times 10^{9}$ cells. $\mathrm{L}^{-1}$ increased, as the cut-off has been associated with significant disease severity and increased risk of exacerbations in chronic airway disease $[5,10,12,16]$.

\section{Definition of chronic airway disease}

The clinical groups of chronic airway disease were defined based on information obtained from the questionnaire and spirometry with the highest likelihood principle in accordance with the agreed 
recommendations from the Global Initiative for Chronic Obstructive Lung Disease (GOLD) and Global Initiative for Asthma (GINA) [17, 18].

Information on asthma and tobacco smoking was obtained through self-report. Asthma was defined as an affirmative response to the question "do you have asthma?" Smoking status was defined as never-, former and current smokers. Based on information on age at smoking onset, duration of tobacco smoking and amount of tobacco consumed, we calculated smoking history (cumulative tobacco consumption) in pack-years for former and current smokers; 1 pack-year corresponded to 20 cigarettes or equivalent (e.g. cheroots, cigars, pipe), smoked daily for 1 year.

Spirometry was performed using an EasyOne Spirometer (ndd Medical Technologies, Zurich, Switzerland) in a standing position without the use of a nose-clip. Prebronchodilator forced expiratory volume in $1 \mathrm{~s}$ $\left(\mathrm{FEV}_{1}\right)$ and forced vital capacity (FVC) were measured with at least three sets of values, and a validated spirometry performance was based on at least two measurements differing by $<5 \%$ and a correct visual inspection of the spirometry curves. Spirometry use in the CGPS has undergone a rigorous validation process [19]. Individuals with presence of airflow limitation, defined as a prebronchodilator FEV1/FVC ratio $<0.70$ were additionally asked to undergo reversibility testing: postbronchodilator FEV1 and FVC were measured using the same procedures $15 \mathrm{~min}$ after inhalation of $400 \mu \mathrm{g}$ salbutamol, a $\beta_{2}$-agonist, from a dry powder inhaler (Ventoline Diskus; GlaxoSmithKline, Brentford, UK). Percentage of predicted values were calculated separately for men and women using internally derived reference values based on a subsample of healthy asymptomatic never-smokers with age and height as covariates [19]. The lower limit

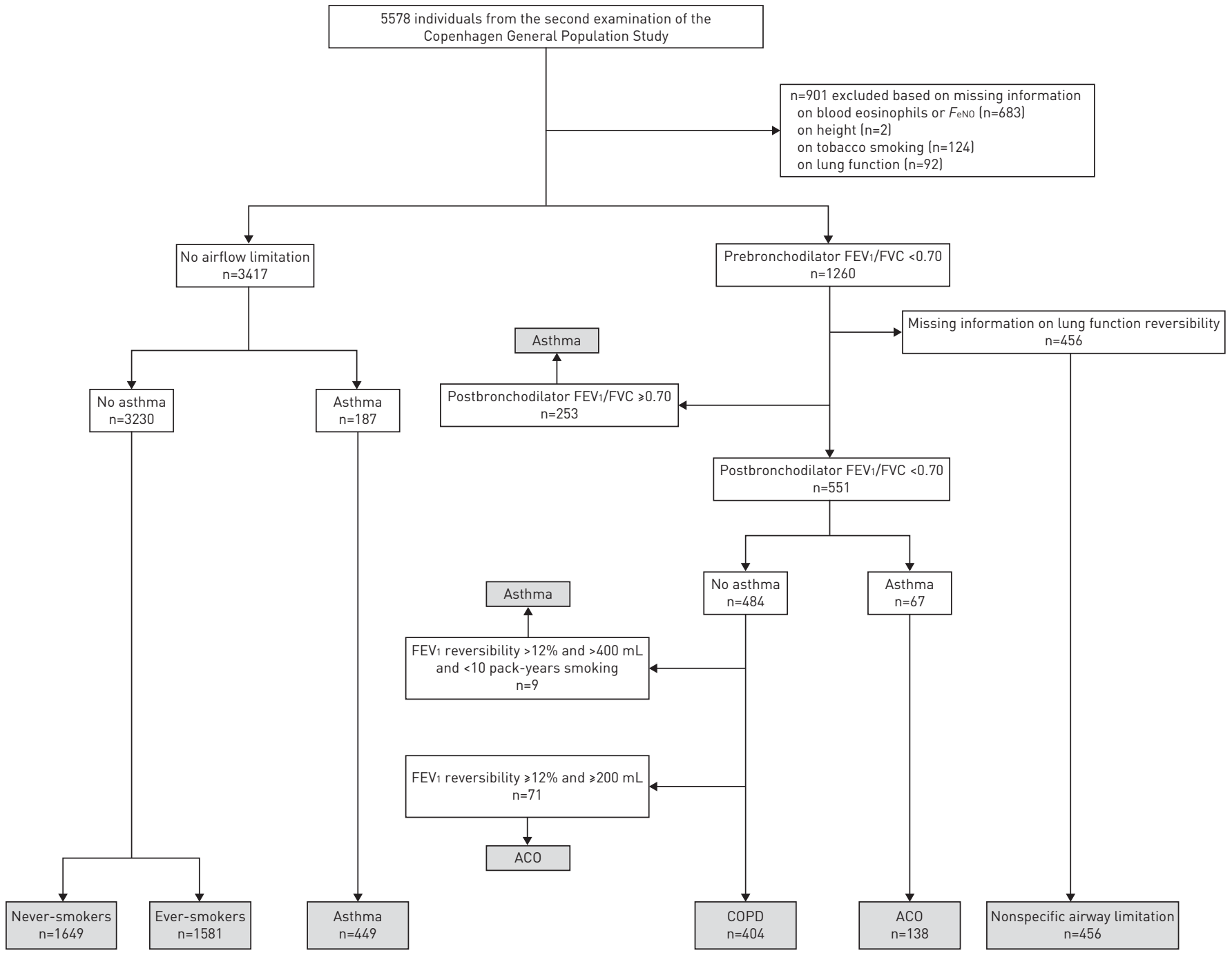

FIGURE 1 Flow chart of the study population. FeNO: exhaled nitric oxide fraction; FEV1: forced expiratory volume in 1 s; FVC: forced vital capacity; ACO: asthma-chronic obstructive pulmonary disease (COPD) overlap. 
TABLE 1 Characteristics of individuals from the Copenhagen General Population Study according to clinical groups of chronic airway disease

Never-smokers Ever-smokers Asthma COPD ACO Nonspecific airflow
limitation

\begin{tabular}{|c|c|c|c|c|c|c|}
\hline Subjects & 1649 & 1581 & 449 & 404 & 138 & 456 \\
\hline Age years & $58(49-68)$ & $60(51-68)$ & $60(51-70)$ & $68(60-75)$ & $68(59-75)$ & $67(59-74)$ \\
\hline Male & $700(42)$ & $745(47)$ & 142 (32) & $220(54)$ & $58(42)$ & $218(48)$ \\
\hline BMI $\mathrm{kg} \cdot \mathrm{m}^{-2}$ & $26(23-29)$ & $27(24-30)$ & $25(23-29)$ & $25(23-28)$ & $26(23-29)$ & $25(23-28)$ \\
\hline FEV1 \% pred & 102 (93-110) & 99 (90-108) & 94 (85-104) & 81 (69-94) & $68(55-79)$ & 85 (71-97) \\
\hline FVC \% pred & 104 (95-112) & 102 (92-111) & 105 (94-116) & 104 (89-117) & 90 (78-103) & 102 (88-116) \\
\hline FEV $1 /$ FVC & $0.78(0.75-0.81)$ & $0.77(0.74-0.80)$ & $0.69(0.67-0.75)$ & $0.62(0.57-0.66)$ & $0.58(0.53-0.63)$ & $0.67(0.60-0.69)$ \\
\hline Current smokers & NA & $335(21)$ & 55 (12) & $100(25)$ & $40(29)$ & $87(19)$ \\
\hline $\begin{array}{l}\text { Smoking history } \\
\text { pack-years }{ }^{\#}\end{array}$ & NA & $14(5-25)$ & 15 (5-27) & $31(18-45)$ & $35(18-50)$ & $24(10-38)$ \\
\hline $\begin{array}{l}\text { Familial predisposition to } \\
\text { COPD }\end{array}$ & $250(15)$ & $265(17)$ & $74(16)$ & $87(22)$ & $46(33)$ & $88(19)$ \\
\hline $\begin{array}{l}\text { Familial predisposition to } \\
\text { asthma }\end{array}$ & $208(13)$ & $201(13)$ & $106(24)$ & $53(13)$ & $32(23)$ & $71(16)$ \\
\hline $\begin{array}{l}\text { Familial predisposition to } \\
\text { allergy" }\end{array}$ & 315 (19) & $246(16)$ & 99 (22) & $41(10)$ & $17(12)$ & $61(13)$ \\
\hline $\begin{array}{l}\text { Childhood asthma or } \\
\text { allergy }\end{array}$ & 315 (19) & $253(16)$ & $137(31)$ & $68(17)$ & $31(22)$ & $92(20)$ \\
\hline Allergy & $593(36)$ & $485(31)$ & $239(53)$ & $110(27)$ & $63(46)$ & $153(34)$ \\
\hline Use of airway medication & $16(1)$ & $18(1)$ & $138(31)$ & 50 (12) & $61(44)$ & $74(16)$ \\
\hline \multicolumn{7}{|l|}{ Respiratory symptoms } \\
\hline Wheezing & $138(8)$ & $247(16)$ & 148 (33) & $104(26)$ & $66(48)$ & 105 (23) \\
\hline Sputum production & $87(5)$ & $177(11)$ & 78 (17) & 77 (19) & $36(26)$ & $73(16)$ \\
\hline Chronic cough & $76(5)$ & 138 (9) & $60(13)$ & $64(16)$ & $26(19)$ & $54(12)$ \\
\hline Dyspnoea & $397(24)$ & 525 (33) & 202 (45) & $217(54)$ & 79 (57) & $198(43)$ \\
\hline Daytime symptoms & 142 (9) & 219 (14) & $135(30)$ & $120(30)$ & 54 (39) & 106 (23) \\
\hline Night-time symptoms & $100(6)$ & 133 (8) & $74(16)$ & $46(11)$ & $29(21)$ & 54 (12) \\
\hline \multicolumn{7}{|l|}{$\begin{array}{l}\text { Degree of airflow } \\
\text { limitation }\end{array}$} \\
\hline $\mathrm{FEV}_{1} \geqslant 80 \%$ pred & 1561 (95) & 1441 (91) & $379(84)$ & $217(54)$ & $32(23)$ & $265(58)$ \\
\hline FEV $150-79 \%$ pred & $85(5)$ & $137(9)$ & $68(15)$ & 159 (39) & $81(59)$ & $162(36)$ \\
\hline FEV $130-49 \%$ pred & $2(<1)$ & $2(<1)$ & $2(<1)$ & $26(6)$ & $24(17)$ & $23(5)$ \\
\hline FEV $1<30 \%$ pred & $1(<1)$ & $1(<1)$ & $0(0)$ & $2(<1)$ & $1(<1)$ & $6(1)$ \\
\hline \multicolumn{7}{|l|}{$\begin{array}{l}\text { Levels of inflammatory } \\
\text { biomarkers }\end{array}$} \\
\hline $\begin{array}{l}\text { Blood eosinophils } \\
\times 10^{9} \text { cells } \cdot L^{-1}\end{array}$ & $0.15(0.10-0.22)$ & $0.16(0.11-0.24)$ & $0.16(0.11-0.27)$ & $0.18(0.12-0.26)$ & $0.19(0.13-0.28)$ & $0.18(0.12-0.27)$ \\
\hline FeNO ppb & $13(10-19)$ & $12(8-17)$ & $14(9-21)$ & $12(8-18)$ & $12(6-21)$ & 13 (8-19) \\
\hline
\end{tabular}

Data are presented as $\mathrm{n}$, median (25th and 75th percentile) or $\mathrm{n}(\%)$, unless otherwise stated. COPD: chronic obstructive pulmonary disease; ACO: asthma-COPD overlap; BMI: body mass index; FEV1: forced expiratory volume in $1 \mathrm{~s}$; FVC: forced vital capacity; FeNO: exhaled nitric oxide fraction; NA: not applicable. "\# : only for former and current smokers; "ः: included the answer: "do not know".

of normal (LLN), defined as the lower 5th percentile of the predicted value for FEV1 and FEV1/FVC, was calculated as the mean value minus $1.645 \mathrm{SD}$.

In total, 4677 individuals were available with sufficient information on relevant measurements, of whom 1260 had prebronchodilator airflow limitation with FEV1/FVC $<0.70$. Among these individuals, 456 declined to perform a reversibility test and, therefore, lacked information on postbronchodilator values. We subdivided participants into the following six groups (figure 1). 1) Healthy never-smokers: never-smokers with prebronchodilator $\mathrm{FEV} / \mathrm{FVC} \geqslant 0.70$ and no self-reported asthma; 2) healthy ever-smokers: former and current smokers with prebronchodilator $\mathrm{FEV}_{1} / \mathrm{FVC} \geqslant 0.70$ and no self-reported asthma; 3) asthma: individuals with prebronchodilator $\mathrm{FEV} 1 / \mathrm{FVC} \geqslant 0.70$ and self-reported asthma, or with prebronchodilator $\mathrm{FEV} 1 / \mathrm{FVC}<0.70$ and postbronchodilator $\mathrm{FEV} 1 / \mathrm{FVC} \geqslant 0.70$, or with pre- and postbronchodilator $\mathrm{FEV} 1 / \mathrm{FVC}<0.70$ and who, despite no self-reported asthma have FEV1 reversibility of $>12 \%$ and $>400 \mathrm{~mL}$ and $<10$ pack-years of smoking history; 4) COPD: individuals with pre- and postbronchodilator FEV1/FVC $<0.70$ and no self-reported asthma or FEV1 reversibility (FEV1 reversibility of $<12 \%$ and $<200 \mathrm{~mL}$ ); 5) ACO: individuals with pre- and post-bronchodilator $\mathrm{FEV} 1 / \mathrm{FVC}<0.70$ and 

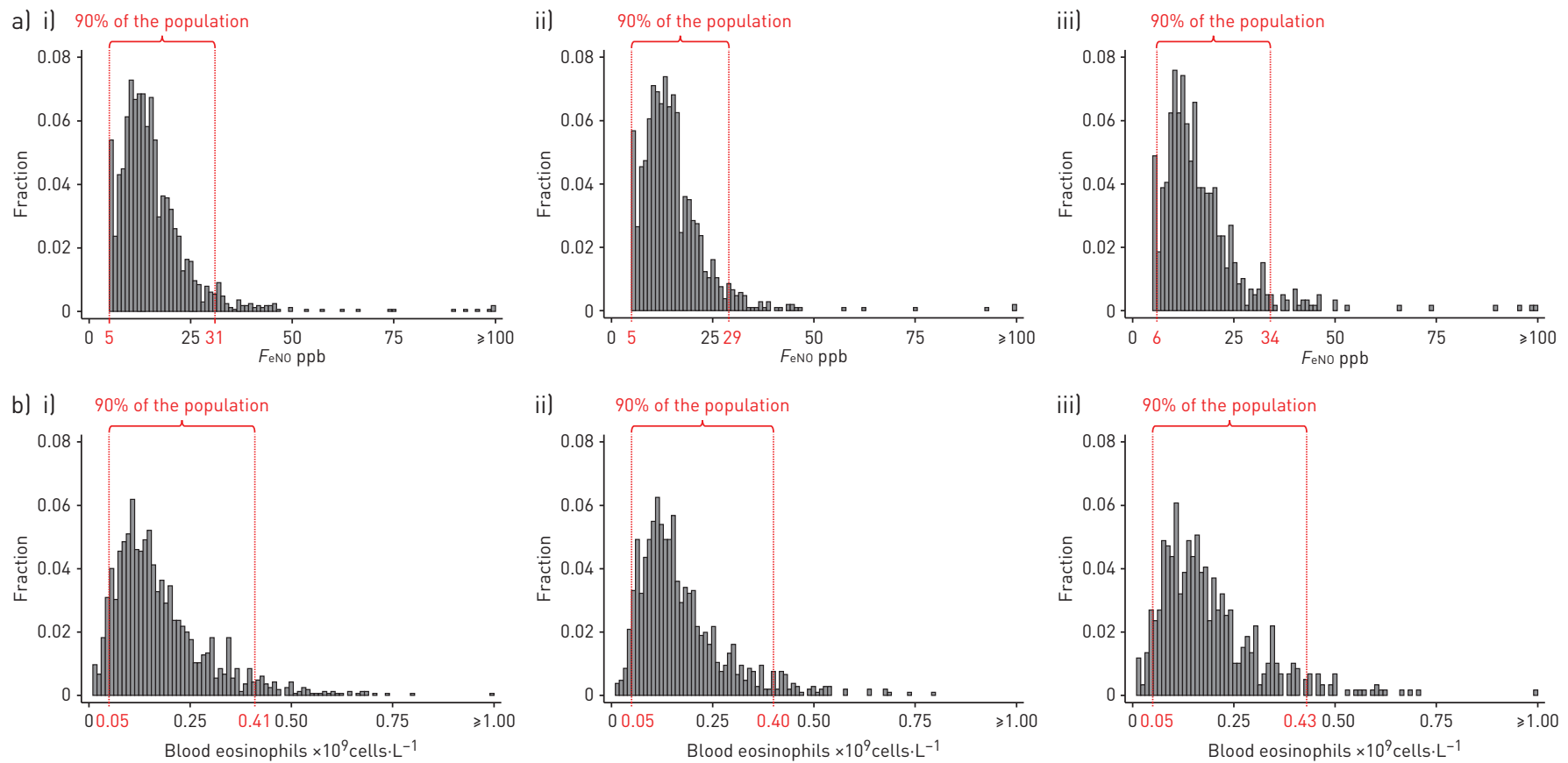

FIGURE 2 Distribution of a) exhaled nitric oxide fraction ( $F_{\mathrm{eNO}}$ ) levels and b) blood eosinophil counts in i) healthy never-smokers ii) without and iii) with atopy.

self-reported asthma or with pre- and postbronchodilator $\mathrm{FEV} 1 / \mathrm{FVC}<0.70$ and who, despite no self-reported asthma have FEV1 reversibility of $\geqslant 12 \%$ and $\geqslant 200 \mathrm{~mL}$; 6) nonspecific airflow limitation: individuals with prebronchodilator $\mathrm{FEV} 1 / \mathrm{FVC}<0.70$ and no reversibility testing.

\section{Other information}

Body mass index (BMI) was calculated as measured weight divided by measured height squared $\left(\mathrm{kg} \cdot \mathrm{m}^{-2}\right)$. Familial predisposition was defined as at least one first-degree relative (father, mother and/or sibling) with the condition in question. Allergy was defined if the participants reported to have allergy for different allergens (i.e. mould fungus, pollens from trees, grasses or weeds, dust mites, pets or other allergens) or asthma, hay fever or eczema as a reaction to food, medications, grass, flowers, animal hair or other allergens. In addition, information on childhood asthma or allergy was self-reported. Use of airway medication was defined as taking any kind of medication for asthma/bronchitis (including sprays/dry powders) daily or almost daily. Wheezing was whistling or wheezing while breathing. Sputum production was phlegm from the lungs in the morning and/or during the day for three consecutive months each year. Chronic cough was cough lasting $>8$ weeks. Dyspnoea was shortness of breath during different levels of activity, at night-time and/or while seated/at rest. Individuals were asked whether they had respiratory symptoms during the day or at night.

\section{Statistical analyses}

Statistical analyses were performed using STATA/SE 13.1 for Windows (StataCorp, College Station, TX, USA). Logistic regression models were used. Area under the curve (AUC) for the receiver operating characteristics and classification statistics were determined; the positive outcome thresholds were estimated by plotting the sensitivity and specificity versus probability cut-off. First, associations of clinical attributes with an increased FeNO level and blood eosinophil count were investigated. Second, associations of an increased FeNO level and blood eosinophil count with symptoms and type of chronic airway disease were investigated. Third, predictive capabilities of the two biomarkers were investigated in a clinical population reporting at least one respiratory symptom (i.e. wheezing, sputum production, chronic cough, dyspnoea and respiratory symptoms during the day or at night). All prediction analyses were adjusted for age and sex. All analyses for the two biomarkers were performed separately and combined.

\section{Results}

Among 4677 individuals, 1649 were healthy never-smokers, 1581 were healthy ever-smokers, 449 had asthma, 404 had COPD, 138 had ACO and 456 had nonspecific airflow limitation (figure 1). Individuals with COPD, ACO and nonspecific airflow limitation were older compared to the other groups (table 1). 
a)

Age (per 10 years higher) Sex (males versus females) BMI (per $10 \mathrm{~kg} \cdot \mathrm{m}^{-2}$ higher) Current smoking Smoking history (per 10 pack-years higher) Familial predisposition to COPD Familial predisposition to asthma Familial predisposition to allergy Childhood asthma or allergy Allergy

Use of airway medication

$\mathrm{FEV}_{1} \%$ pred $<\mathrm{LLN}$

$\mathrm{FEV}_{1} / \mathrm{FVC}<\mathrm{LLN}$

$\mathrm{FEV}_{1}<80 \%$ pred

$\mathrm{FEV}_{1} / \mathrm{FVC}<0.70$

Postbronchodilator $\mathrm{FEV}_{1} / \mathrm{FVC}<0.70$

Reversibility

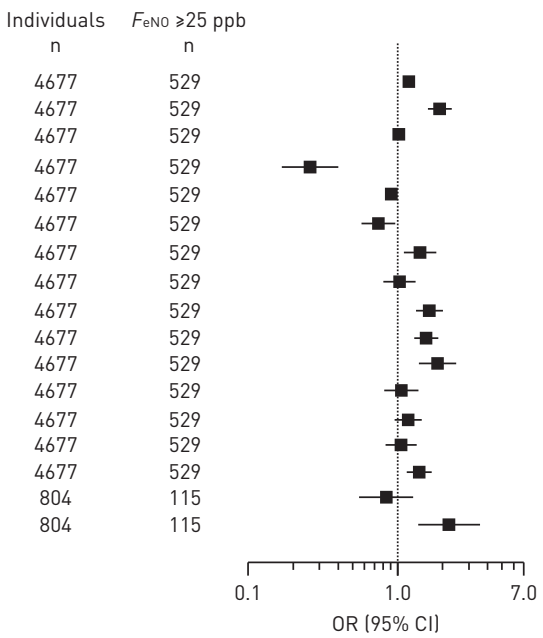

OR $(95 \% \mathrm{CI})$

p-value

$1.19(1.11-1.28) \quad 3 \times 10^{-6}$

$1.92(1.59-2.30) \quad 4 \times 10^{-12}$

$1.02(0.98-1.06)-0.37$

$0.26(0.17-0.40) \quad 1 \times 10^{-9}$

$0.91(0.86-0.96) \quad 0.001$

$0.75(0.57-0.97) \quad 0.03$

$1.41(1.10-1.82) \quad 0.007$

$1.03(0.80-1.32) \quad 0.82$

$1.63(1.32-2.01) \quad 4 \times 10^{-6}$

$1.55(1.29-1.87) \quad 3 \times 10^{-6}$

$1.85(1.39-2.46) \quad 3 \times 10^{-5}$

$1.06(0.81-1.38) \quad 0.68$

$1.18(0.95-1.45)-0.13$

$1.06(0.83-1.34) \quad 0.66$

$\begin{array}{ll}1.06(0.83-1.34) & 0.66 \\ 1.40(1.15-1.69) & 8 \times 10^{-4}\end{array}$

$0.84(0.55-1.27) \quad 0.41$

$2.21(1.37-3.56) \quad 0.001$

b)

Age (per 10 years higher)

Sex (males versus females)

BMI (per $10 \mathrm{~kg} \cdot \mathrm{m}^{-2}$ higher)

Current smoking

Smoking history (per 10 pack-years higher)

Familial predisposition to COPD

Familial predisposition to asthma

Familial predisposition to allergy

Childhood asthma or allergy

Allergy

Use of airway medication

FEV $1 \%$ pred $<$ LLN

$\mathrm{FEV}_{1} / \mathrm{FVC}<\mathrm{LLN}$

$\mathrm{FEV}_{1}<80 \%$ pred

$\mathrm{FEV}_{1} / \mathrm{FVC}<0.70$

Postbronchodilator $\mathrm{FEV}_{1} / \mathrm{FVC}<0.70$

Reversibility

c)

Age (per 10 years higher)

Sex (males versus females)

BMI (per $10 \mathrm{~kg} \cdot \mathrm{m}^{-2}$ higher)

Current smoking

Smoking history (per 10 pack-years higher)

Familial predisposition to COPD

Familial predisposition to asthma

Familial predisposition to allergy

Childhood asthma or allergy

Allergy

Use of airway medication

$\mathrm{FEV}_{1} \%$ pred $<\mathrm{LLN}$

$\mathrm{FEV}_{1} / \mathrm{FVC}<\mathrm{LLN}$

$\mathrm{FEV}_{1}<80 \%$ pred

$\mathrm{FEV}_{1} / \mathrm{FVC}<0.70$

Postbronchodilator $\mathrm{FEV}_{1} / \mathrm{FVC}<0.70$

Reversibility
Blood eosinophils $\geqslant 0.3 \times 10^{-9}$ cells $\cdot \mathrm{L}^{-1}$

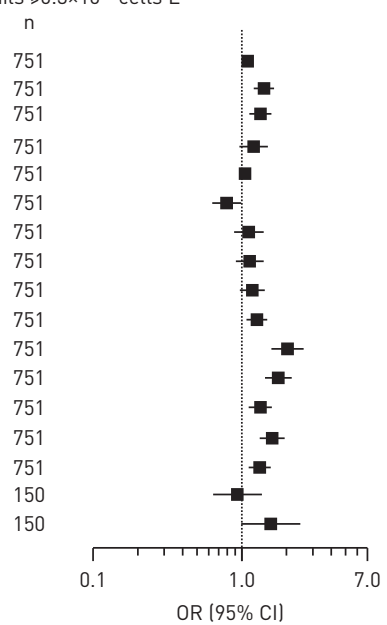

OR $(95 \%$ CI)

p-value

$1.09(1.03-1.16)$

$1.41(1.20-1.65)$

$1.33(1.12-1.58)$

$1.20(0.96-1.50)$

$1.05(1.01-1.10)$

$0.79(0.63-0.99)$

$1.11(0.89-1.40)$

$1.13(0.91-1.40)$

$1.17(0.97-1.42)$

$1.26(1.08-1.48)$

$2.03(1.58-2.60)$

$1.76(1.43-2.17)$

$1.33(1.11-1.59)$

$1.60(1.32-1.94)$

$1.32(1.11-1.56)$

$0.93(0.64-1.37)$

$1.57(0.99-2.48)$

0.005

$2 \times 10^{-5}$

0.001

0.10

0.009

0.04

0.36

0.26

0.10

0.004

$3 \times 10^{-8}$

$8 \times 10^{-8}$

0.002

$2 \times 10^{-6}$

0.001

0.73

0.06

$F_{\mathrm{eNO}} \geqslant 25 \mathrm{ppb}$ and

blood eosinophils $\geqslant 0.3 \times 10^{-9}$ cells. L $^{-1}$

$n$
151
151
151
151
151
151
151
151
151
151
151
151
151
151
151
38
38

.

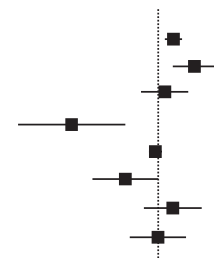

OR $(95 \% \mathrm{Cl})$

p-value

$1.26(1.10-1.44) \quad 7 \times 10^{-4}$

$1.73(1.25-2.41) \quad 0.001$

$1.10(0.77-1.58) \quad 0.61$

$0.27(0.12-0.60) \quad 0.002$

$0.96(0.87-1.05) \quad 0.37$

$0.60(0.37-1.00) \quad 0.048$

$1.25(0.80-1.94) \quad 0.33$

$0.99(0.64-1.53) \quad 0.97$

$1.54(1.06-2.22) \quad 0.02$

$1.85(1.34-2.56) \quad 2 \times 10^{-4}$

$3.46(2.30-5.19) \quad 2 \times 10^{-9}$

$1.79(1.20-2.69) \quad 0.005$

$1.51(1.06-2.16) \quad 0.02$

$1.71(1.17-2.49) \quad 0.005$

$1.78(1.27-2.48) \quad 7 \times 10^{-4}$

$0.62(0.32-1.19) \quad 0.15$

$3.25(1.61-6.56) \quad 0.001$

FIGURE 3 Clinical attributes associated with a) increased exhaled nitric oxide fraction ( $F_{\mathrm{eNO}}$; $\geqslant 25 \mathrm{ppb}$ ): b) increased blood eosinophil count $\left(\geqslant 0.3 \times 10^{9}\right.$ cells. $\left.L^{-1}\right)$; and c) combined value. Reversibility was defined as forced expiratory volume in $1 \mathrm{~s}$ (FEV 1 ) reversibility of $\geqslant 12 \%$ and $\geqslant 200 \mathrm{~mL}$. Logistic regression models were used. Estimates are unadjusted. p-values were from Wald's test. BMI: body mass index; COPD: chronic obstructive pulmonary disease; LLN: lower limit of normal; FVC: forced vital capacity. 


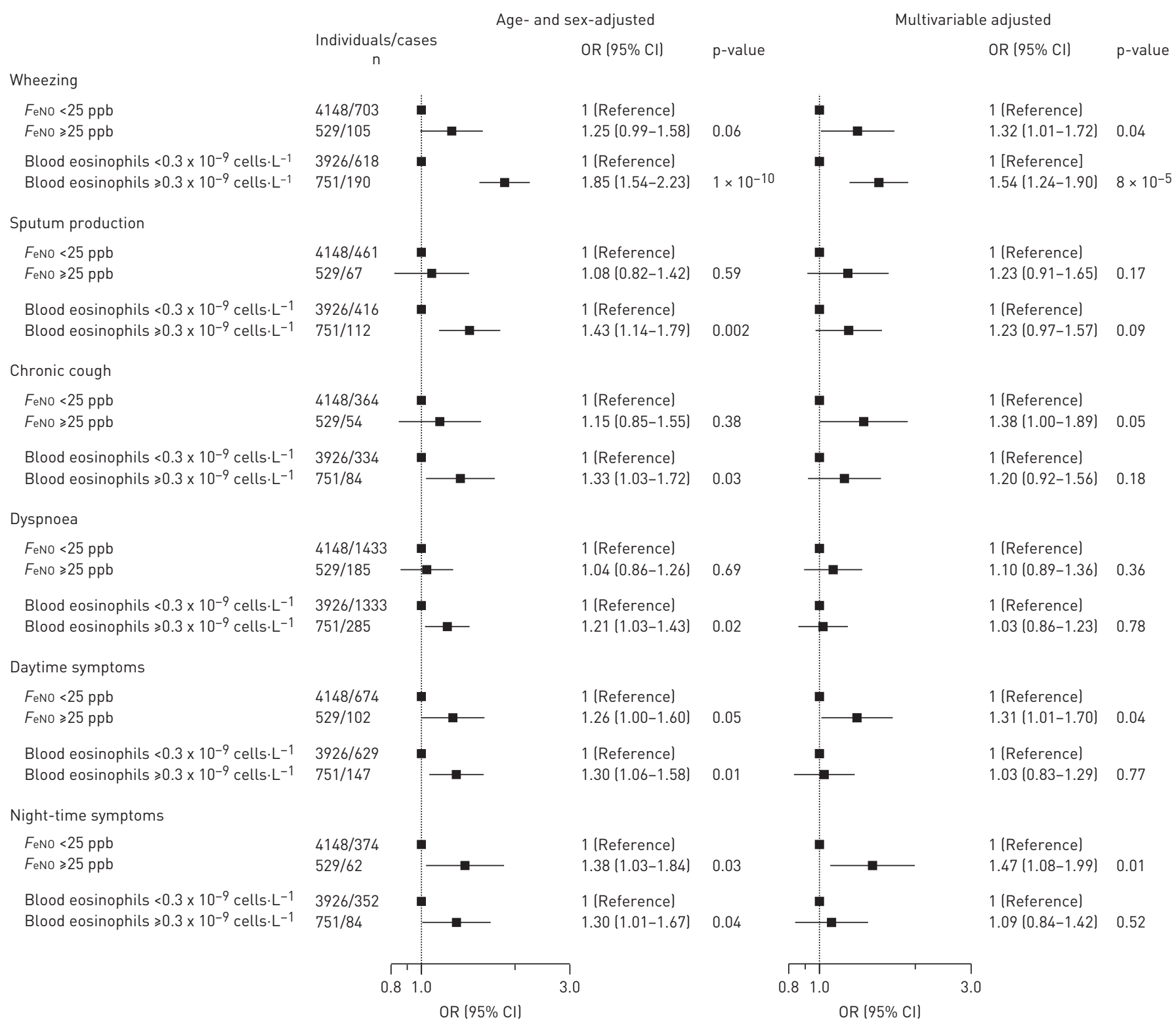

FIGURE 4 Separate association of increased exhaled nitric oxide level and blood eosinophil count with respiratory symptoms. Logistic regression models were used. Multivariable adjustment included age, sex, body mass index, smoking status, smoking history, familial predisposition for chronic obstructive pulmonary disease and asthma, atopy and use of airway medication. p-values were from Wald's test. Feno: exhaled nitric oxide fraction.

Individuals with asthma, COPD and particularly those with ACO had lower lung function and reported more symptoms and greater use of airway medication. Generally, healthy individuals with atopy compared to those without atopy irrespective of smoking status seemed to have higher FeNO levels and blood eosinophil counts, while healthy current smokers compared to healthy never- and former smokers irrespective of presence of atopy seemed to have lower FeNO levels and higher blood eosinophil counts (figure 2 and online supplementary figures S1-S4).

\section{Clinical attributes}

A higher age, male sex, prebronchodilator $\mathrm{FEV} 1 / \mathrm{FVC}<0.70$, positive reversible test, self-reported atopy and use of airway medication were all associated with an increased risk of having a FeNO level $\geqslant 25 \mathrm{ppb}$ and a blood eosinophil count $\geqslant 0.3 \times 10^{9}$ cells $\cdot \mathrm{L}^{-1}$, both when analysed separately and combined (figure 3 ). In contrast, only higher BMI, prebronchodilator FEV1/FVC $<$ LLN and FEV1 \% pred $<$ LLN and $<80 \%$ were associated with an increased risk of having a blood eosinophil count $\geqslant 0.3 \times 10^{9}$ cells $\cdot \mathrm{L}^{-1}$, whereas current smoking and smoking history were associated with a reduced risk of having a FeNO level $\geqslant 25 \mathrm{ppb}$. 


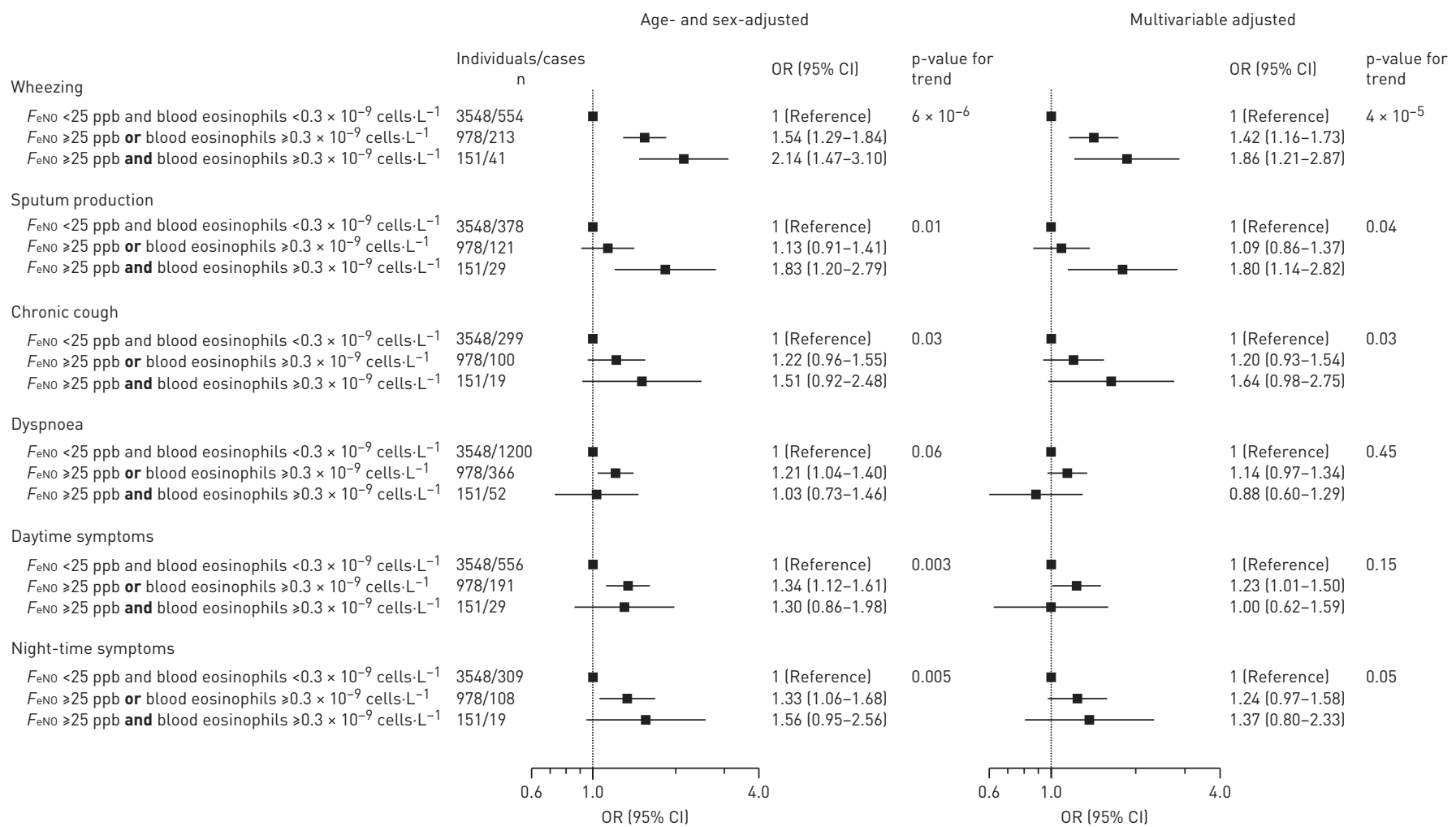

FIGURE 5 Combined association of increased exhaled nitric oxide level and blood eosinophil count with respiratory symptoms. Logistic regression models were used. Multivariable adjustment included age, sex, body mass index, smoking status, smoking history, familial predisposition to chronic obstructive pulmonary disease and asthma, atopy and use of airway medication. p-values were from Wald's test. Feno: fraction of exhaled nitric oxide.

\section{Respiratory symptoms}

An increased FeNO level was associated with an increased risk of wheezing and respiratory symptoms during the day and at night, whereas an increased blood eosinophil count was associated with an increased risk of all types of respiratory symptoms (figure 4). These associations were attenuated after additional adjustment for potential confounders. Compared to individuals with FeNO level $<25 \mathrm{ppb}$ and blood eosinophil count $<0.3 \times 10^{9}$ cells $\cdot \mathrm{L}^{-1}$, age- and sex-adjusted odds ratios $(95 \% \mathrm{CI}$ ) for wheezing were 1.54 $(1.29-1.84)$ for individuals with $F$ eNO level $\geqslant 25 \mathrm{ppb}$ or blood eosinophil count $\geqslant 0.3 \times 10^{9}$ cells $\cdot \mathrm{L}^{-1}$ and 2.14 (1.47-3.10) for individuals with FeNO level $\geqslant 25 \mathrm{ppb}$ and blood eosinophil count $\geqslant 0.3 \times 10^{9}$ cells $\cdot \mathrm{L}^{-1}$ (figure 5). Corresponding odds ratios (95\% CI) were $1.13(0.91-1.41)$ and $1.83(1.20-2.79)$ for sputum production, $1.22(0.96-1.55)$ and $1.51(0.92-2.48)$ for chronic cough, $1.21(1.04-1.40)$ and 1.03 (0.73-1.46) for dyspnoea, $1.34(1.12-1.61)$ and $1.30(0.86-1.98)$ for daytime respiratory symptoms and $1.33(1.06-1.68)$ and $1.56(0.95-2.56)$ for night-time respiratory symptoms. Results were attenuated but similar after additional adjustment for potential confounders.

\section{Chronic airway disease}

When the two biomarkers were analysed separately, an increased FeNO level and blood eosinophil count were associated with an increased risk of asthma, but not COPD or ACO (figure 6). Compared to individuals with $F$ eNO level $<25 \mathrm{ppb}$ and blood eosinophil count $<0.3 \times 10^{9} \mathrm{cells} \cdot \mathrm{L}^{-1}$, age- and sex-adjusted odds ratios $(95 \% \mathrm{CI})$ for asthma were $1.54(1.22-1.94)$ for individuals with FeNO level $\geqslant 25 \mathrm{ppb}$ or blood eosinophil count $\geqslant 0.3 \times 10^{9}$ cells $\cdot \mathrm{L}^{-1}$ and $3.26(2.16-4.94)$ for individuals with FeNO level $\geqslant 25 \mathrm{ppb}$ and blood eosinophil count $\geqslant 0.3 \times 10^{9}$ cells $\cdot \mathrm{L}^{-1}$. Corresponding odds ratios $(95 \% \mathrm{CI})$ were $1.03(0.80-1.32)$ and $0.67(0.36-1.27)$ for COPD and $1.32(0.88-1.96)$ and 2.14 (1.05-4.36) for ACO. Adjustment for additional potential confounders gave attenuated but similar results. Results were similar when defining the clinical groups of obstructive lung disease according to FEV1/FVC <LLN (online supplementary figure S5).

In additional analyses, we restricted to different subgroups of individuals with chronic airway disease. In the subgroup of individuals with asthma and COPD, an increased FeNO level and blood eosinophil count was associated with an increased risk of asthma compared to COPD, especially when the two biomarkers were combined (figure 7). Similarly, when individuals with COPD and ACO were analysed separately, an 


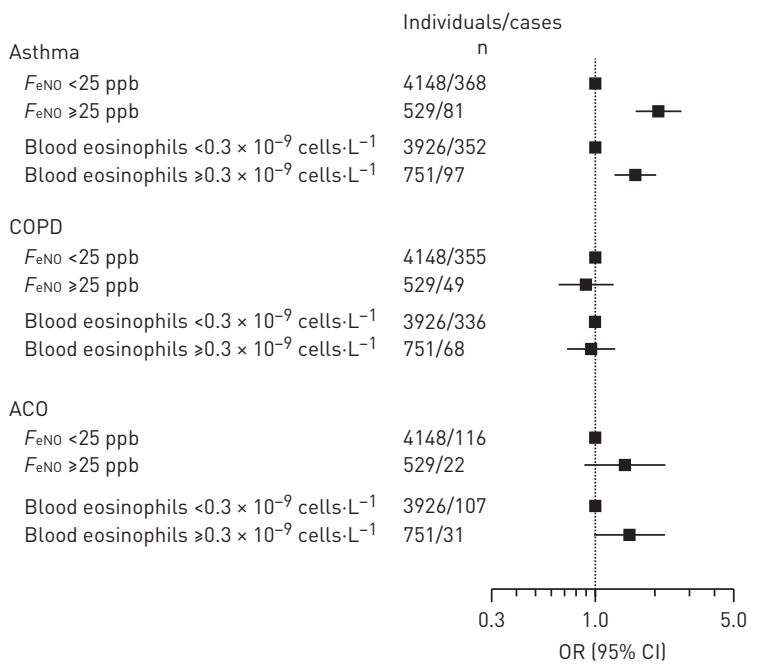

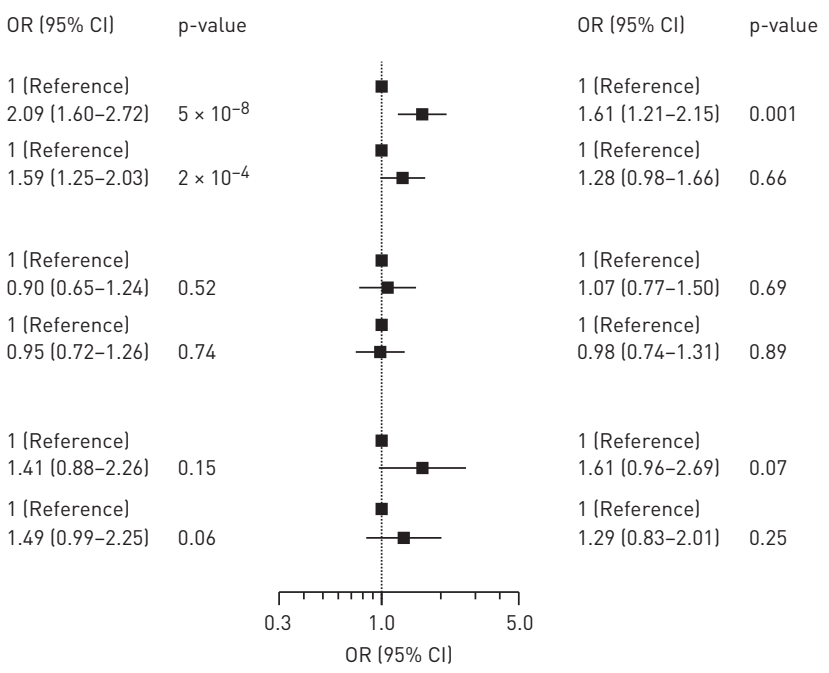

b)

Age- and sex-adjusted
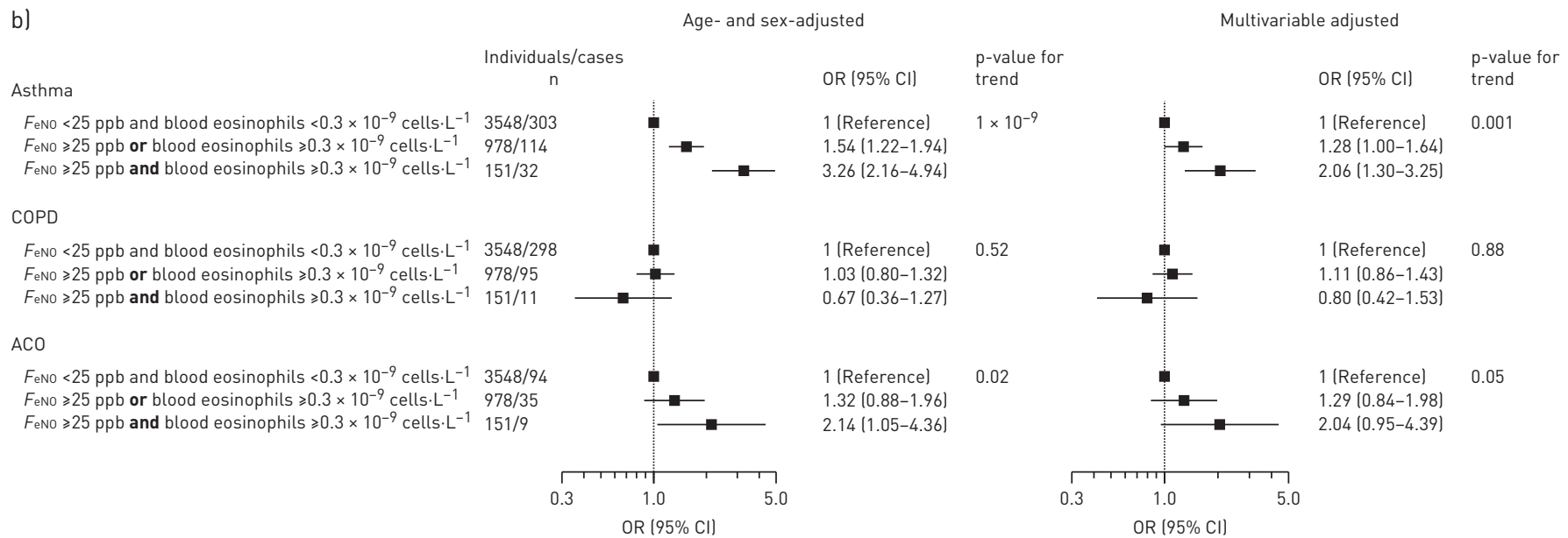

FIGURE 6 Association of increased exhaled nitric oxide level and blood eosinophil count with asthma, chronic obstructive pulmonary disease (COPD) and asthma-COPD overlap (ACO). a) Separate association analyses; b) combined association analyses. Logistic regression models were used. Multivariable adjustment included age, sex, body mass index, smoking status, smoking history, familial predisposition to COPD and asthma, atopy and use of airway medication. p-values were from Wald's test. FeNO: exhaled nitric oxide fraction.

increased FeNO level and blood eosinophil count was associated with an increased risk of ACO compared to COPD. No clear associations were observed in the ACO and asthma subgroup.

\section{Predictive capabilities}

Among individuals reporting respiratory symptoms, FeNO and blood eosinophils had a poor sensitivity and specificity with regard to predicting asthma, COPD or ACO (table 2). Furthermore, the negative predictive value was high $(\geqslant 90 \%)$ and the positive predictive value was low $(\leqslant 18 \%)$. No differences were observed between the two biomarkers, and the combination of them did not seem to improve the predictive capability. AUC (95\% CI) values for predicting asthma were $0.62(0.58-0.65)$ for $F$ eNO $\geqslant 25 \mathrm{ppb}$, $0.60(0.57-0.64)$ for blood eosinophils $\geqslant 0.3 \times 10^{9}$ cells $\cdot \mathrm{L}^{-1}$ and $0.61(0.58-0.64)$ for $F \mathrm{eNO} \geqslant 25 \mathrm{ppb}$ and/or blood eosinophils $\geqslant 0.3 \times 10^{9}$ cells $\cdot \mathrm{L}^{-1}$. Corresponding AUC $(95 \% \mathrm{CI})$ values were $0.68(0.65-0.72), 0.68$ $(0.64-0.71)$ and $0.69(0.65-0.72)$ for COPD and $0.63(0.57-0.68), 0.64(0.59-0.69)$ and $0.64(0.59-0.69)$ for ACO.

After restricting the analyses to subgroups with chronic airway disease, no differences could be observed between the two biomarkers and the combination of them with regard to the predictive capability of differentiating between asthma, COPD or ACO. Although the overall predictive capabilities were poor, the two biomarkers seemed to have an acceptable performance with regard to differentiating between asthma and COPD. 
a)

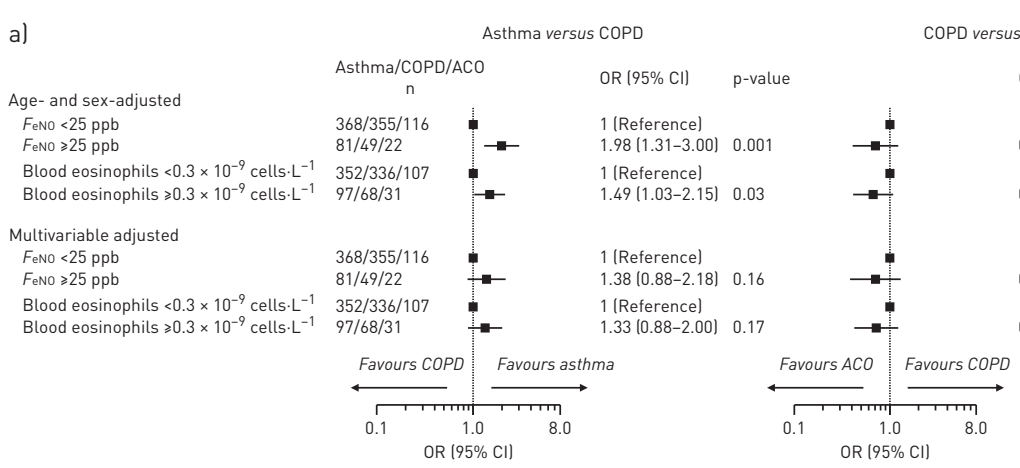

COPD versus ACO

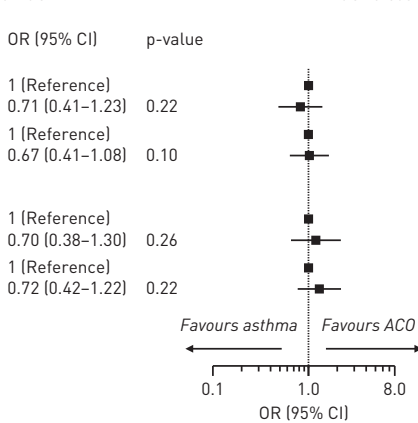

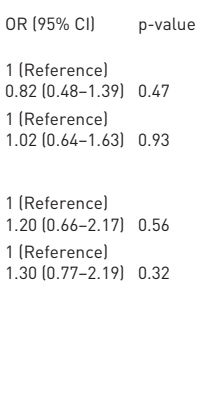

b)

Asthma versus COPD

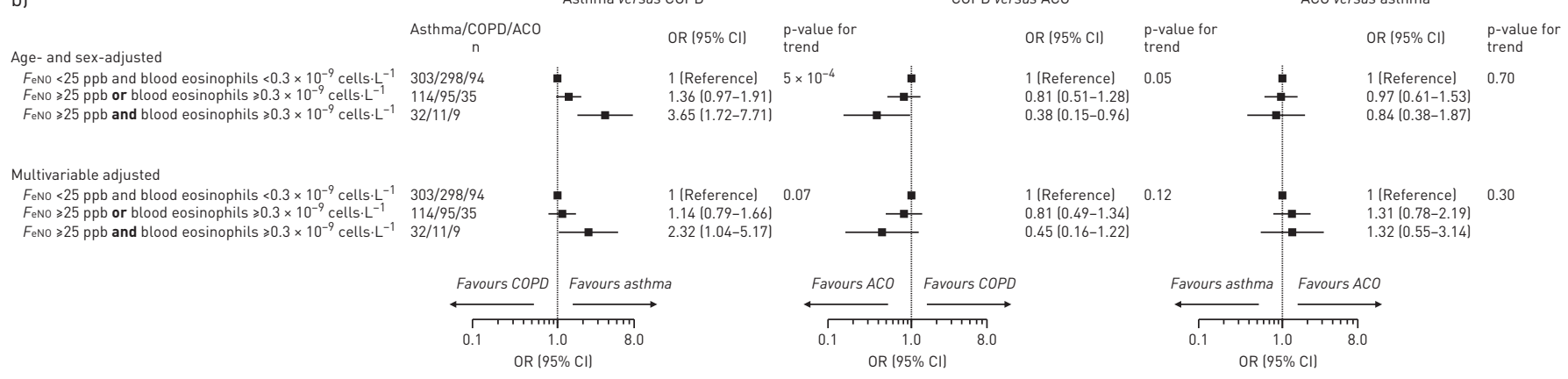

FIGURE 7 Increased exhaled nitric oxide level and blood eosinophil count favouring more asthma, chronic obstructive pulmonary disease (COPD) or asthma-COPD overlap (ACO). a) Separate association analyses; b) combined association analyses. Logistic regression models were used. Multivariable adjustment included age, sex, body mass index, smoking status, smoking history, familial predisposition to COPD and asthma, atopy and use of airway medication. p-values were from Wald's test. Feno: exhaled nitric oxide fraction.

\section{Discussion}

In this large random sample from the general population, we found that compared to individuals with normal FeNO level and blood eosinophil count, individuals with both increased biomarkers had an increased risk of respiratory symptoms and asthma and ACO with higher risk estimates than those with only one increased biomarker. Among individuals reporting respiratory symptoms, predicting the type of chronic airway disease did not differ between the two biomarkers and did not improve by combining them; however, use of the two biomarkers seemed to rule out chronic airway disease with a negative predictive value of $\geqslant 90 \%$. Thus, our findings suggest that although the combination of these two biomarkers may have an additive value in characterising chronic airway disease, it still needs to be investigated further with regard to potential clinical application.

Exhaled nitric oxide is believed to arise due to local inflammation in the airways related to the activation of interleukin (IL)-4 and IL-13, whereas blood eosinophils are believed to reflect systemic inflammation with the activation of interleukin IL-5 [2]. In large clinical trials, treatment with mepolizumab (monoclonal anti-IL-5) reduced blood eosinophil counts significantly without any noteworthy effect on FeNO levels [7-9], while treatment with lebrikizumab (anti-IL-13) and dupilumab (anti-IL-4 and -13) reduced FeNO levels significantly with no or a very modest increase in blood eosinophil counts [4, 6]. This suggests that these two biomarkers should not be used interchangeably, but instead be combined in order to determine different aspects of an eosinophilic airway inflammation. In the present study, we observed not only an additive value of combining these two biomarkers, but that these biomarkers were differently associated with some of the clinical attributes when analysed separately. A greater airflow limitation, a well-known clinical attribute of severe obstructive lung disease [20,21], was associated with an increased risk of having a blood eosinophil count $\geqslant 0.3 \times 10^{9}$ cells $\cdot \mathrm{L}^{-1}$ but not with FeNO level $\geqslant 25 \mathrm{ppb}$. Furthermore, measures of atopy and smoking were associated with FeNO rather than with blood eosinophils.

Another interesting finding was that both an increased FeNO level and blood eosinophil count were associated with asthma and ACO, but not with COPD. We do not necessarily believe that FeNO and blood eosinophils are able to differentiate asthma and ACO from COPD, but rather identify a pathophysiological trait more common in asthma and ACO rather than in COPD [22]. However, the use of FeNO and blood eosinophils had low sensitivity and specificity among symptomatic individuals for diagnosing the type of chronic airway disease, suggesting that the two biomarkers have their limitations and should be more thoroughly investigated in clinical studies before implementation in routine practice. Yet, the two 
TABLE 2 Predictive capabilities of increased exhaled nitric oxide level and blood eosinophil count with regard to chronic airway disease in symptomatic individuals

Sensitivity Specificity PPV NPV AUC $195 \% \mathrm{CIl}$ p-value versus p-value versus blood p-value versus Fevo

FenO

eosinophils

and blood eosinophils

\section{Asthma}

$F_{\mathrm{eNO}} \geqslant 25 \mathrm{ppb}$

Blood eosinophils $\geqslant 0.3 \times 10^{9}$ cells. $L^{-1}$

$F_{\mathrm{eNO}} \geqslant 25 \mathrm{ppb}$ and/or blood eosinophils $\geqslant 0.3 \times 10^{9}$ cells. $\mathrm{L}^{-1}$

COPD

FeNO $\geqslant 25 \mathrm{ppb}$

Blood eosinophils $\geqslant 0.3 \times 10^{9}$ cells $\cdot \mathrm{L}^{-1}$

$F_{\mathrm{eNO}} \geqslant 25 \mathrm{ppb}$ and/or blood eosinophils $\geqslant 0.3 \times 10^{9}$ cells. $\mathrm{L}^{-1}$

$F_{\mathrm{eNO}} \geqslant 25 \mathrm{ppb}$

Blood eosinophils $\geqslant 0.3 \times 10^{9}$ cells $\cdot \mathrm{L}^{-1}$

$F_{\text {eNO }} \geqslant 25 \mathrm{ppb}$ and/or blood eosinophils $\geqslant 0.3 \times 10^{9}$ cells $\cdot \mathrm{L}^{-1}$

Asthma versus COPD

$F_{\mathrm{eNO}} \geqslant 25 \mathrm{ppb}$

Blood eosinophils $\geqslant 0.3 \times 10^{9}$ cells. $L^{-1}$

$F_{\mathrm{eNO}} \geqslant 25 \mathrm{ppb}$ and/or blood eosinophils $\geqslant 0.3 \times 10^{9}$ cells. $\mathrm{L}^{-1}$

COPD versus $A C O$

$F_{\mathrm{eNO}} \geqslant 25 \mathrm{ppb}$

Blood eosinophils $\geqslant 0.3 \times 10^{9}$ cells. $L^{-1}$

$F_{\mathrm{eNO}} \geqslant 25 \mathrm{ppb}$ and/or blood eosinophils $\geqslant 0.3 \times 10^{9}$ cells $\mathrm{L}^{-1}$

ACO versus asthma

$F_{\text {eNO }} \geqslant 25 \mathrm{ppb}$

Blood eosinophils $\geqslant 0.3 \times 10^{9}$ cells. $\mathrm{L}^{-1}$

FeNO $\geqslant 25 \mathrm{ppb}$ and/or blood eosinophils $\geqslant 0.3 \times 10^{9}$ cells $\cdot \mathrm{L}^{-1}$

\begin{tabular}{|c|c|c|c|c|c|c|c|}
\hline 57 & 60 & 18 & 90 & $0.62(0.58-0.65)$ & NA & 0.10 & 0.36 \\
\hline 61 & 55 & 17 & 90 & $0.60(0.57-0.64)$ & 0.10 & NA & 0.16 \\
\hline 58 & 59 & 18 & 90 & $0.61(0.58-0.64)$ & 0.36 & 0.16 & NA \\
\hline 61 & 64 & 18 & 93 & $0.68(0.65-0.72)$ & NA & 0.26 & 0.37 \\
\hline 60 & 64 & 18 & 92 & $0.68(0.64-0.71)$ & 0.26 & NA & 0.12 \\
\hline 60 & 64 & 18 & 93 & $0.69(0.65-0.72)$ & 0.37 & 0.12 & NA \\
\hline 54 & 64 & 7 & 97 & $0.63(0.57-0.68)$ & NA & 0.34 & 0.10 \\
\hline 57 & 66 & 7 & 97 & $0.64(0.59-0.69)$ & 0.34 & NA & 0.89 \\
\hline 51 & 66 & 7 & 97 & $0.64(0.59-0.69)$ & 0.10 & 0.89 & NA \\
\hline 67 & 66 & 69 & 64 & $0.74(0.70-0.78)$ & NA & 0.32 & 0.27 \\
\hline 67 & 65 & 69 & 63 & $0.73(0.69-0.77)$ & 0.32 & NA & 0.08 \\
\hline 67 & 67 & 70 & 64 & $0.74(0.70-0.78)$ & 0.27 & 0.08 & NA \\
\hline 58 & 57 & 77 & 35 & $0.57(0.50-0.64)$ & NA & 0.51 & 0.26 \\
\hline 50 & 66 & 79 & 34 & $0.59(0.52-0.65)$ & 0.51 & NA & 0.94 \\
\hline 59 & 58 & 78 & 36 & $0.58(0.52-0.65)$ & 0.26 & 0.94 & NA \\
\hline 59 & 63 & 35 & 82 & $0.68(0.62-0.74)$ & NA & 0.94 & 0.69 \\
\hline 63 & 60 & 35 & 83 & $0.68(0.62-0.74)$ & 0.94 & NA & 0.86 \\
\hline 62 & 62 & 36 & 83 & $0.68(0.63-0.74)$ & 0.69 & 0.86 & NA \\
\hline
\end{tabular}

Data are presented as \%, unless otherwise stated. Individuals reported to have at least one respiratory symptom (i.e. wheezing, sputum production, chronic cough, dyspnoea and respiratory symptoms during the day or at night). Logistic regression models were used to calculate the statistics and included age and sex as covariates. $\mathrm{p}$-values were from testing the equality of two areas under the curve (AUC) for the receiver operating characteristics. PPV: positive predictive value; NPV: negative predictive value; $F$ eNO: exhaled nitric oxide fraction; COPD: chronic obstructive pulmonary disease; ACO: asthma-COPD overlap; NA: not applicable. 
biomarkers had a negative predictive value of $\geqslant 90 \%$ and therefore seem to be useful for excluding presence of chronic airway disease among symptomatic individuals in a general population setting. Since the positive and negative predictive values are also dependent on the prevalence of the disease irrespective of the sensitivity and specificity, a potential explanation for observing a high negative predictive value in combination with a low sensitivity and specificity in the present study may be the low prevalence of chronic airway disease in the present sample of the general population.

Previous studies have shown an increased FeNO level and blood eosinophil count to be independently associated with increased disease severity and acute attacks among patients with asthma and COPD [12, 16, 23-26]. However, the additive value of combining these two biomarkers has not been investigated extensively. In the National Health and Nutrition Examination Survey, combining FeNO and blood eosinophils gave an additive value with regard to determining risk of current asthma, wheezing, asthma attack and asthma-related emergency department visits $[5,11]$. Furthermore, the same investigators could also observe an additive value by combining the two biomarkers among asthmatic individuals with regard to determining severity of airflow limitation, degree of bronchial responsiveness, and having uncontrolled asthma and frequent asthma attacks [10]. Lastly, since the majority of individuals with asthma in the present study had mild disease, the median values of FeNO and blood eosinophils were lower compared to those with a more severe disease, which is often seen in secondary care [27].

An important limitation of the present study includes the definitions of the clinical groups of chronic airway disease. Despite the differentiation between reversible and irreversible airflow limitation, both asthma and COPD are very complex diseases with regard to clinical presentation and natural history and may be difficult to separate, and in particular the definition of ACO is still controversial. Although we had a highest likelihood principle to define the clinical groups by taking the agreed recommendations from GOLD and GINA into account [18], our findings warrant replication in clinical settings, where more detailed characterisation of type of chronic airway disease is possible. Another limitation was that we were unable to determine the type of used airway medication. Lastly, although spirometry use in the CGPS has previously undergone a rigorous validation process, some of the procedures were not in accordance with the recommendations from the ERS and ATS [28].

In conclusion, the combination of FeNO and blood eosinophils may have an additive value in characterising chronic airway disease in the general population, but still needs to be investigated further with regard to clinical application.

Author contributions: Y. Colak and S. Afzal had full access to all of the data in the study and take responsibility for the integrity of the data and the accuracy of the data analyses. Study concept and design: Y. Çolak, S. Afzal, B.G. Nordestgaard, J.L. Marott and P. Lange. Acquisition, analyses, or interpretation of data: Y. Çolak, S. Afzal, B.G. Nordestgaard, J.L. Marott and P. Lange. Drafting of the manuscript: Y. Çolak. Critical revision of the manuscript for important intellectual content: Y. Çolak, S. Afzal, B.G. Nordestgaard, J.L. Marott and P. Lange. Statistical analyses: Y. Çolak and S. Afzal. Obtained funding: B.G. Nordestgaard and P. Lange. Administrative, technical, or material support: B.G. Nordestgaard. Study supervision: P. Lange.

Conflict of interest: Y. Çolak reports personal fees from Boehringer Ingelheim and AstraZeneca outside the submitted work. P. Lange reports grants from AstraZeneca and GlaxoSmithKline, and personal fees from Boehringer Ingelheim, AstraZeneca, Novartis and GlaxoSmithKline, outside the submitted work.

Support statement: The Lundbeck Foundation, the Dept of Internal Medicine and Dept of Clinical Biochemistry at Herlev and Gentofte Hospital, and the Danish Lung Association. The funders had no role in the design and conduct of the study; collection, management, analysis or interpretation of the data; preparation, review or approval of the manuscript; or decision to submit the manuscript for publication. Funding information for this article has been deposited with the Crossref Funder Registry.

\section{References}

1 George L, Brightling CE. Eosinophilic airway inflammation: role in asthma and chronic obstructive pulmonary disease. Ther Adv Chronic Dis 2016; 7: 34-51.

2 Pavord ID, Beasley R, Agusti A, et al. After asthma: redefining airways diseases. Lancet 2018; 391: 350-400.

3 Pavord ID, Afzalnia S, Menzies-Gow A, et al. The current and future role of biomarkers in type 2 cytokine-mediated asthma management. Clin Exp Allergy 2017; 47: 148-160.

4 Corren J, Lemanske RF, Hanania NA, et al. Lebrikizumab treatment in adults with asthma. N Engl J Med 2011; 365: 1088-1098.

5 Malinovschi A, Fonseca JA, Jacinto T, et al. Exhaled nitric oxide levels and blood eosinophil counts independently associate with wheeze and asthma events in National Health and Nutrition Examination Survey subjects. J Allergy Clin Immunol 2013; 132: 821-827.

6 Wenzel S, Ford L, Pearlman D, et al. Dupilumab in persistent asthma with elevated eosinophil levels. $N$ Engl J Med 2013; 368: 2455-2466.

7 Haldar P, Brightling CE, Hargadon B, et al. Mepolizumab and exacerbations of refractory eosinophilic asthma. $N$ Engl J Med 2009; 360: 973-984. 
8 Ortega HG, Liu MC, Pavord ID, et al. Mepolizumab treatment in patients with severe eosinophilic asthma. $N$ Engl J Med 2014; 371: 1198-1207.

9 Pavord ID, Korn S, Howarth P, et al. Mepolizumab for severe eosinophilic asthma (DREAM): a multicentre, double-blind, placebo-controlled trial. Lancet 2012; 380: 651-659.

10 Malinovschi A, Janson C, Borres M, et al. Simultaneously increased fraction of exhaled nitric oxide levels and blood eosinophil counts relate to increased asthma morbidity. J Allergy Clin Immunol 2016; 138: 1301-1308.

11 Pavord ID, Bafadhel M. Exhaled nitric oxide and blood eosinophilia: independent markers of preventable risk. J Allergy Clin Immunol 2013; 132: 828-829.

12 Vedel-Krogh S, Nielsen SF, Lange P, et al. Blood eosinophils and exacerbations in chronic obstructive pulmonary disease. The Copenhagen General Population Study. Am J Respir Crit Care Med 2016; 193: 965-974.

13 Çolak Y, Afzal S, Nordestgaard BG, et al. Prognosis of asymptomatic and symptomatic, undiagnosed COPD in the general population in Denmark: a prospective cohort study. Lancet Respir Med 2017; 5: 426-434.

14 American Thoracic Society, European Respiratory Society. ATS/ERS recommendations for standardized procedures for the online and offline measurement of exhaled lower respiratory nitric oxide and nasal nitric oxide, 2005. Am J Respir Crit Care Med 2005; 171: 912-930.

15 Dweik RA, Boggs PB, Erzurum SC, et al. An official ATS clinical practice guideline: interpretation of exhaled nitric oxide levels $\left(F \mathrm{E}_{\mathrm{NO}}\right)$ for clinical applications. Am J Respir Crit Care Med 2011; 184: 602-615.

16 Price DB, Rigazio A, Campbell JD, et al. Blood eosinophil count and prospective annual asthma disease burden: a UK cohort study. Lancet Respir Med 2015; 3: 849-858.

17 Lange P, Colak Y, Ingebrigtsen TS, et al. Long-term prognosis of asthma, chronic obstructive pulmonary disease, and asthma-chronic obstructive pulmonary disease overlap in the Copenhagen City Heart study: a prospective population-based analysis. Lancet Respir Med 2016; 4: 454-462.

18 Global Initiative for Asthma (GINA), Global Initiative for Chronic Obstructive Lung Disease (GOLD). Diagnosis of Diseases of Chronic Airflow Limitation: Asthma, COPD, and Asthma-COPD Overlap Syndrome (ACOS). www. goldcopd.org/asthma-copd-asthma-copd-overlap-syndrome Date last accessed: March 13, 2018.

19 Løkke A, Marott JL, Mortensen J, et al. New Danish reference values for spirometry. Clin Respir J 2013; 7: 153-167.

20 Global Initiative for Chronic Obstructive Lung Disease (GOLD). Global Strategy for the Diagnosis, Management, and Prevention of Chronic Obstructive Lung Disease. www.goldcopd.org/gold-reports Date last accessed: March 13,2018

21 Global Initiative for Asthma (GINA). Global Strategy for Asthma Management and Prevention. www.ginasthma. org/2018-gina-report-global-strategy-for-asthma-management-and-prevention/ Date last accessed: March 13, 2018.

22 Agusti A, Bel E, Thomas M, et al. Treatable traits: toward precision medicine of chronic airway diseases. Eur Respir J 2016; 47: 410-419.

23 Alcázar-Navarrete B, Ruiz Rodríguez O, Conde Baena P, et al. Persistently elevated exhaled nitric oxide fraction is associated with increased risk of exacerbation in COPD. Eur Respir J 2018; 51: 1701457.

24 Bafadhel M, McKenna S, Terry S, et al. Acute exacerbations of chronic obstructive pulmonary disease: identification of biologic clusters and their biomarkers. Am J Respir Crit Care Med 2011; 184: 662-671.

25 Bjerregaard A, Laing IA, Backer V, et al. High fractional exhaled nitric oxide and sputum eosinophils are associated with an increased risk of future virus-induced exacerbations: a prospective cohort study. Clin Exp Allergy 2017; 47: 1007-1013.

26 Coumou H, Westerhof GA, de Nijs SB, et al. Predictors of accelerated decline in lung function in adult-onset asthma. Eur Respir J 2018; 51: 1701785.

27 Schleich FN, Chevremont A, Paulus V, et al. Importance of concomitant local and systemic eosinophilia in uncontrolled asthma. Eur Respir J 2014; 44: 97-108.

28 Miller MR, Hankinson J, Brusasco V, et al. Standardisation of spirometry. Eur Respir J 2005; 26: 319-338. 